\title{
Impacts of air pollution on health: evidence from longitudinal cohort data of patients with cardiovascular diseases
}

\author{
Clifford Afoakwah ${ }^{1 *}$ \\ Son Nghiem ${ }^{1}$ \\ Paul Scuffham ${ }^{1,2}$ \\ Quan Huynh ${ }^{3}$ \\ Tom Marwick ${ }^{3}$ \\ Joshua Byrnes $^{1}$ \\ ${ }^{1}$ Centre for Applied Health Economics, Griffith University, Australia \\ ${ }^{2}$ Menzies Health Institute Queensland, Griffith University, Australia \\ ${ }^{3}$ The Baker Heart and Diabetes Institute \\ *Corresponding author, Centre for Applied Health Economics, Griffith University, \\ Nathan QLD 4111, Australia. Tel: +61737359105 \\ Email: c.afoakwah@griffith.edu.au
}

\section{Acknowledgement}

We are grateful to the two anonymous referees for their suggestions on improving the earlier version of the manuscript. This paper was presented at the Brown Bag Seminar Series at the Centre for Applied Finance and Economics (CAFÉ), University of South Australia, Adelaide, Australia. We are grateful to the participants for their comments. This project benefitted financially from National Health and Medical Research Council (NHMRC): Program grant number 1055214 and Centre for Research Excellence (CRE) grant number 1044897. 


\begin{abstract}
This study uses longitudinal cohort data to estimate the impacts of air pollution on health outcomes among people first hospitalised with heart diseases. Despite the generally low level of pollution in Australia, we find that acute exposure to pollution increases readmissions to hospitals within 3-12 months after discharge and is more evident among those suffering from heart failure. We further show that chronic exposure to air pollution increases the risk of death within 72 months, hospital admissions and general practitioner (GP) visits. Patients with coronary heart disease or cerebrovascular disease are the most affected groups. Finally, a costsaving of $\$ 1.3$ billion will be generated to the health sector if the monthly concentration of $\mathrm{PM}_{10}$ and $\mathrm{CO}$ were lowered to $15.49 \mathrm{ug} / \mathrm{m} 3$ and $122.99 \mathrm{ug} / \mathrm{m} 3$ respectively. The findings from our study emphasize the need for policies that target significant reduction in ambient $\mathrm{PM}_{10}$ and $\mathrm{CO}$ in order to decrease the demand for scarce healthcare resources for cardiac diseases.
\end{abstract}

Keywords: Air pollution, cardiovascular disease, health outcomes, cost-savings.

JEL classification: I10, I18 


\section{Introduction}

Air pollution continues to pose a major health threat globally. About 4.2 million deaths in 2016 were attributed to exposure to ambient air pollution [1]. The concentration of pollution across the globe varies significantly across regions, countries and states. Australia, compared to many countries in Organisation for Economic Co-operation and Development (OECD), has low levels of concentration of air pollutants. However, there are several reasons why we should still be concerned with the health impacts of exposure to air pollution even at the current levels. First, the World Health Organisation (WHO) estimates that about 17 people (per 100,000 population) die every year due to exposure to ambient air pollution, and disability-adjusted life years (DALYs) (per 100,000 population) attributable to ambient air pollution was 289 in 2016 in Australia [1]. Second, the concentration of pollution substantially varies across states in Australia, which is partly due to the frequency of bush fires and dust storms in some parts of the country. Thus, the concentration of pollution in some states exceeds the National Environmental Protection Measure (NEPM) for Air Quality Standards. Third, evidence from Tasmania and the United States shows that even low levels of pollutions can still lead to adverse health outcomes $[2,3]$.

Two important questions remain unanswered: first, to what extent does the current levels of pollution in Australia affect the survival time of people with cardiovascular diseases? Second, what are the costs associated with chronic exposure to air pollution?

Cardiovascular diseases (CVD) is a major health concern globally and Australia is not immune to this problem. CVD affects one in every three persons in Australia and is responsible for one in every four deaths [4]. People with heart diseases are highly at risk of adverse events when exposed to air pollution due to their pre-existing heart conditions. This study investigates the impacts of acute and chronic exposure to air pollution on selected health outcomes using longitudinal cohort data of CVD patients who were first hospitalised in Queensland in 2010 with subsequent admissions until 2015. Specifically, we estimate the impacts of air pollution exposure on 3-month and 12-month readmissions, time-to-death, number of hospital admissions and number of GP visits.

Studies on the health effects of exposure to ambient air pollution are not farfetched. The findings are diverse, and the scope covers two perspectives. The first focuses on children's health. The findings are that exposure to air pollution increases children's asthma admissions $[5,6]$ infant mortality [2], causes low birth weight $[7,8]$ and increases respiratory treatment [9]. The second focuses on adults' health such as hospital admissions, mortality, lung capacity 
and haemoglobin [10-12]. However, the impact of pollution on the health and wellbeing of CVD patients has received little research.

This study adds to the few studies on air pollution and adult health and contributes to the literature in three ways: Firstly, we explore the impact of both acute and chronic exposure to air pollution on health outcomes among a cohort of adults who have been hospitalised with cardiovascular disease with subsequent admissions over six years. The longitudinal nature of our patient-level (unit) data allows us to examine the impact of both acute and chronic exposure to pollution of people's health. Such an analysis is important for designing policies that seek to improve short term health outcomes such as hospital readmission, which imposes a significant cost burden to the health sector. Our second contribution lies in the research design used for estimating the impact of air pollution on death. To the best of our knowledge, no study has conducted a time-to-event analysis of this important nexus. Our rich data allow us to observe the date a patient was first hospitalised as well as the death date, hence, we can model survival time after first hospitalisation. Time-to-death analysis not only estimates the impact of pollution on the mortality risk but also on time the event occurred. Previous studies have focused predominantly on mortality in a time-series framework. However, the time dimension of the mortality risk, especially at the individual level offers useful inputs for policy formulation such as secondary prevention or health care planning, particularly for high-risk groups. Finally, we estimate the amount of healthcare consumption that would be avoided as well as cost-savings to the health sector if air pollution were to be lowered.

This study proceeds as follows: Background information about air pollution and cardiovascular disease is presented in Section 2, which is followed by a discussion on the research design used for the study in Section 3. Section 4 discusses the data while Section 5 presents the results. In Section 6, we conduct some robustness check of our estimates and discuss our main findings in Section 7 before concluding the study.

\section{Background}

Air pollution constitutes the presence of many different small substances in the air. These substances may include particulate matter, carbon monoxide, ozone, nitrogen oxide, sulphur dioxide, among others. In this study, we focus on two main substances that are directly linked with CVD: carbon monoxide (CO) and particulate matter with a diameter of 10 micrometres $\left(\mathrm{PM}_{10}\right) . \mathrm{CO}$ is an odourless, colourless gas which comes from incomplete burning of fossil fuels and fuel burning, boilers, stoves, gas or kerosene heaters, and tobacco smoke 
[13]. It is estimated that about 2,600 million tonnes of carbon monoxide are emitted into the atmosphere globally, of which human activities account for $60 \%$ and the remaining from natural processes [14]. The characteristics of CO makes it a dangerous gaseous pollutant as it requires continuous exposure beyond 232,840 micrograms per cubic metre of air ( $\mathrm{ug} / \mathrm{m} 3$ ) before its effects can be observed [15]. Queensland Environmental Protection has a strict policy that sets the maximum amount of $\mathrm{CO}$ for every 8 hours in a day at $9 \mathrm{ppm}$. CO levels in Queensland have declined over the past decades with current levels less than $20 \%$ of the National Environmental Protection Measures (NEPM) Air Quality Standards. The decline in CO in Queensland is attributed to emission controls such as catalytic converters, especially in urban areas where the largest amount of CO comes from motor vehicles[15]. Such decline is shown is Figure 1 for the two monitoring stations at South East Queensland and Gladstone.

The affinity of CO to bind to haemoglobin is more than 200 times that of the affinity of oxygen $\left(\mathrm{O}_{2}\right)$ to bind to haemoglobin; thus, $\mathrm{CO}$ displaces $\mathrm{O}_{2}$ and renders the haemoglobin nonfunctional [8]. Hence, exposure to CO destroys the haemoglobins and reduces the ability of the red blood cells to carry oxygen to the body parts that need them. Since people with CVD have pre-existing heart conditions, inadequate supply of oxygen to the heart due to the high prevalence of $\mathrm{CO}$ in the red blood cells can trigger adverse events leading to frequents hospital admissions, GP visits or a terminal death condition if emergency services are lacking.

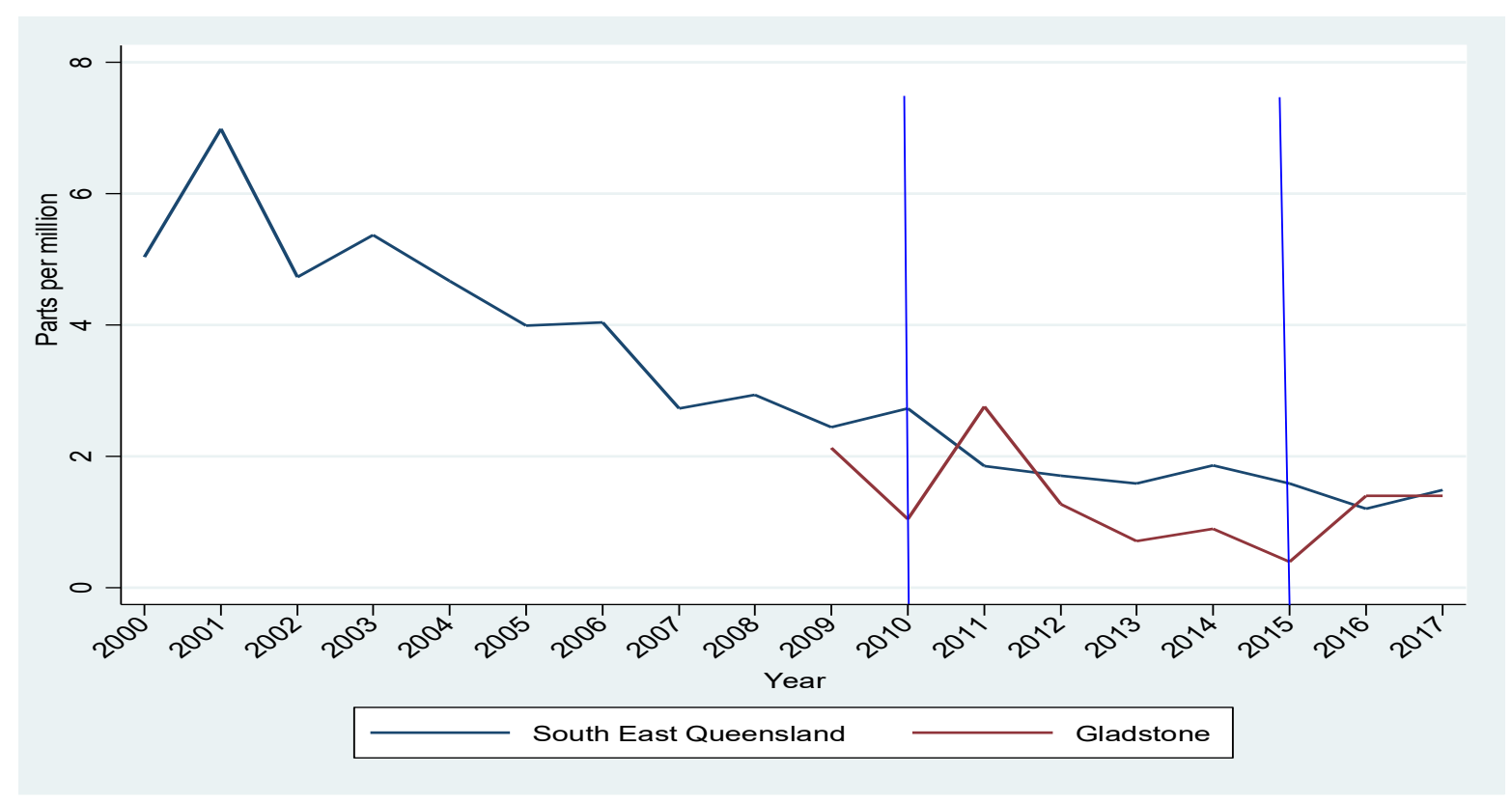

Figure 1: Annual maximum 8-hour average $\mathrm{CO}$ concentration 
$\mathrm{PM}_{10}$, on the other hand, refers to the concentration of tiny particles, which are often sourced from re-suspension, tobacco smoke, combustion products. It is a major air pollution issue in Queensland. According to the Queensland Government State of the Environment (QGSE), this is partly due to particles from dust storms, smoke from bushfires, agricultural burning and hazard reduction[16]. Although the Queensland environmental protection policy sets the maximum amount of $\mathrm{PM}_{10}$ to be equivalent to the National Environmental protection Measures (NEPM) standards of $50 \mathrm{ug} / \mathrm{m} 3$ per 24 hours, concentration levels have often exceeded the limits by an average of 15 days in a year as shown in Figure 2 . The annual number of days when 24 - hour PM10 concentration exceeded NEPM standards was highest particularly in 2012 in Moranbah. This according to the QGSE was due to housing estate development around the monitoring station. For robustness checks, we later exclude Moranbah in the analysis. Exposure to PM10 induces acute and persistent airway and lung inflammations, pulmonary injury, and reduced lung functioning [9]. Chronic intake of $\mathrm{PM}_{10}$ into the lungs provokes oxidative stress, making the lungs unable to resist infectious diseases. The proinflammatory therefore leads to pathological processes including increased thrombosis, hypercoagulability, endothelial dysfunction and insulin resistance [17], leading to adverse health outcomes, especially among people with pre-existing heart conditions

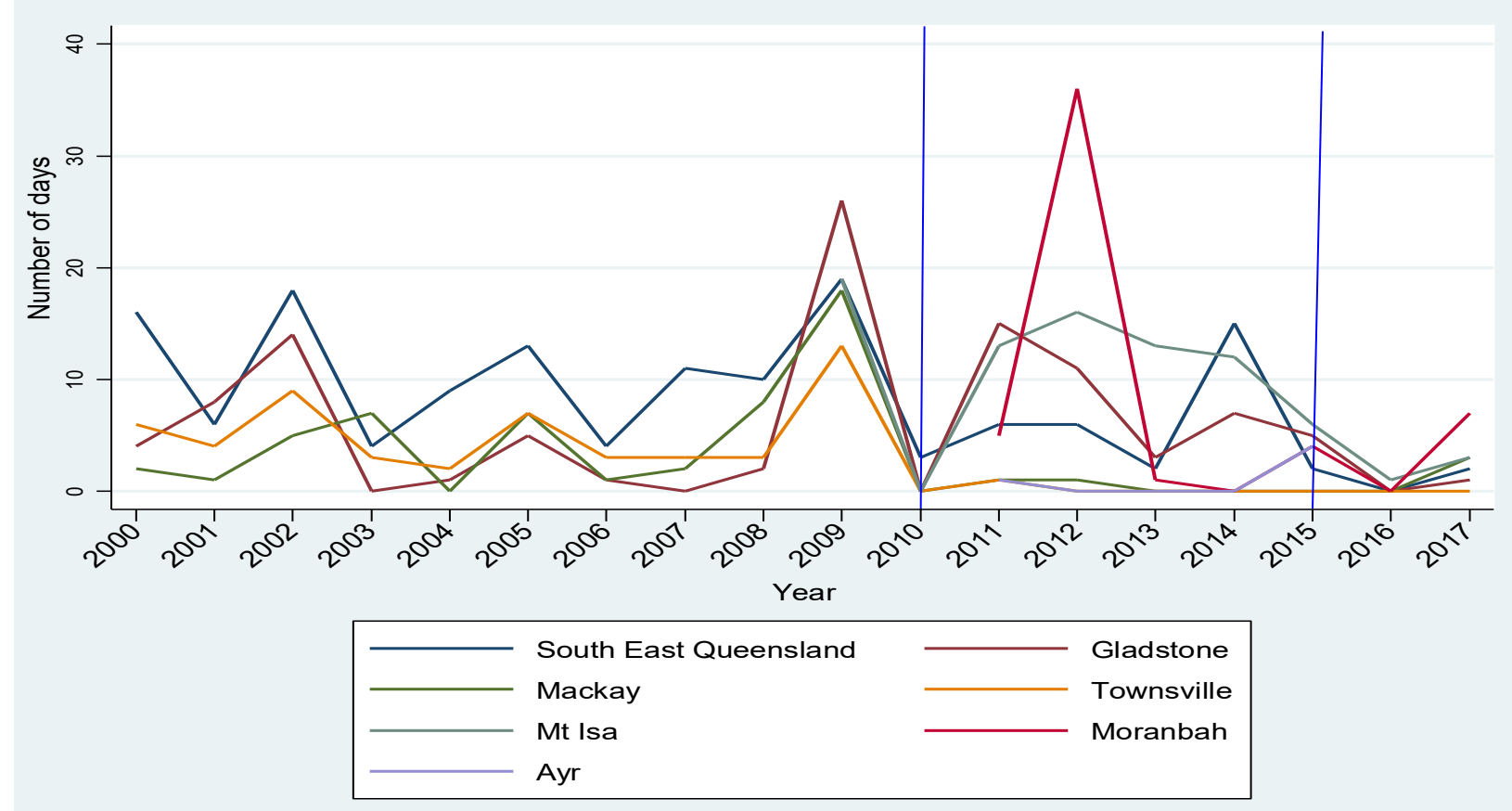

Figure 2: Number of days when 24-hour $\mathrm{PM}_{10}$ in Queensland exceeded NEPM air standards 
CVD in itself involves any disease of the heart and blood vessel. Coronary Heart Disease (CHD), which is the most common type of CVD, ${ }^{1}$ occurs when plaques build up in the heart arteries. The accumulation of plagues narrows the arteries, making it more difficult for blood to flow to the heart [18]. Hence, people with CVD require a regular supply of adequate oxygen to the heart to be able to pump enough blood to the body organs. Epidemiological and medical studies have shown that the exposure to ambient air pollution can cause CVD, and the mechanisms occur through vascular function, vascular compliance, urinary albumin excretion, altered cardiac structure and function, and atherosclerosis[17, 19, 20].

In this study, we analyse longitudinal data on CVD patients to estimate the impact of acute exposure to both $\mathrm{CO}$ and $\mathrm{PM}_{10}$ on readmission within 3 months and 12 months after being discharged from the hospital. We further analyse the impact of chronic exposure to $\mathrm{CO}$ and $\mathrm{PM}_{10}$ on time-to-death, the number of hospital admissions and the number of GP visits within six years after the first hospitalisation.

\section{Research design}

This study utilises two main research designs. The first design is to understand the impact of acute exposure to air pollution after hospital discharge on hospital readmissions. Hospital readmission is often an undesirable outcome for patients and presents a significant burden the hospital resources. By this approach, we can tease out the acute impact of air pollution on readmission. The econometric model for acute exposure on readmission is specified as:

$$
\text { Readmit }_{i t}=\delta \text { Air }_{t}+\varphi X_{t}+\tau_{t}+\varepsilon_{i t}
$$

where Readmit is a binary variable for whether the individual $i$ at period $t$ was readmitted within 3 months or 12 months after hospital discharge; Air is the measure of air pollution exposure, $\mathrm{X}$ is a set of covariates; $\tau$ are time dummies for month and year of admission; and $\varepsilon$ represent random noise. The linear probability model (LPM) is used to estimate equation (1). The advantage of the LPM over other maximum likelihood techniques is that it increases the computation speed substantially while producing consistent results, particularly for large datasets $[21,22]$. Also, the estimated parameters are conveniently interpreted as marginal effects. For robustness check, we also estimated a non-linear logit model and the results are reported in Appendix 1.

\footnotetext{
${ }^{1} 3 \%$ of the Australian adult population was estimated to have CHD in 2017-18.
} 
The second research design explores the impact of chronic exposure to monthly variations in air pollution on health outcomes. This approach allows us the estimate the longterm impact on air pollution on the health of people with CVD. Two empirical strategies are utilised: first, is a time-to-event design, which is used to estimate the effect of chronic exposure to air pollution on time-to-death after index hospitalisation among people with CVD. The semi-parametric Cox proportional hazard model for survival analysis is modelled. The structure of our data allows us to observe the date the individual died; hence, a continuous timevarying hazard model is specified as:

$$
\operatorname{Death}(t)=\operatorname{Death}_{0}(t) \exp \left[\alpha \operatorname{Air}_{t}+\emptyset X_{t}\right]
$$

where $\operatorname{Death}_{0}(t)$ is the common baseline hazard function of death, $\alpha$ measure the impact of air pollution on time-to-death, and $\varnothing$ represent the effect of other covariates on death. The Registrar General's Department (RG) records the date of death of every individual. Hence, individuals who have no death dates are considered to have survived during the study period. We generate a dummy variable for individuals who have an official date of death in the RG database. Survival time, in months, is defined as the difference between the date of death and the date of the first hospitalisation.

The second empirical approach for the impact of chronic exposure to air pollution on the number of chronic outcomes occurring within six years after index hospitalisation, and is specified as:

$$
\text { Outcome }_{i t}=\beta \text { Air }_{t}+\gamma X_{t}+\theta_{t}+\varepsilon_{i t}
$$

where Outcome is a continuous variable for the number of hospital admissions and number of GP visits within six years after the first hospitalisation. The Ordinary Least Squares (OLS) method is used to estimate the air pollution elasticity after converting both dependent and air pollution measure to logged values.

Standard errors in all specifications are adjusted at the individual level to take into account the potential of within-individual correlation between the susceptibility of exposure to air pollution and health status. The impact of air pollution on one's health might confound with the person's health stock during extreme exposures. Therefore, we control for the severity of a person's condition at the time of admission by including a dummy for admission to intensive care unit (ICU) [23]. We also include dummies for age groups to isolate any confounding effects driven by age-related health conditions. 


\section{Data and variables}

Data for the study are linked longitudinal administrative data sets sourced from three different databases: Queensland Hospital Admitted Patient Data Collection (QHAPDC), Emergency Department Information System (EDIS) and the Registrar General Deaths Database (RG). The population includes 135,399 people with a diagnosis of CVD who visited one of the 247 health care facilities in Queensland over the period 2010-2015. CVD patients were classified as those with the first three letters in the ICD-10 primary diagnosis codes in the range from I00 to I99. This includes conditions not limited to Ischaemic heart diseases, cerebrovascular diseases, atrial fibrillation, coronary heart disease and heart failure. We later explore the impact of pollution on the health of people with specific CVD conditions. The study focused on individuals who were first admitted in 2010, which allows us to eliminate the leftcensoring bias[24]. We excluded individuals who were discharged on the same day of visit to the hospital, as well as those who visited the hospital for renal dialysis. This exercise was to avoid assigning a higher weight for those who are more likely to be readmitted to the hospital, which could bias our estimates. The final sample includes 75,140 individuals with a total of 484,963 admission episodes. A detailed description of the cohort can be found in [25].

Air pollution data on $\mathrm{PM}_{10}$ and $\mathrm{CO}$ is sourced from the Queensland Government Department of Environment and Science (QGDES). There are only two CO monitoring stations in Queensland - South East Queensland (with about 75\% of the total population in Queensland) and Gladstone and 30 stations for $\mathrm{PM}_{10}$ across the state. However, data for all monitoring stations for $\mathrm{PM}_{10}$ during the entire study period are not available because individual stations were set up at different time periods [15]. We, therefore, use the mean monthly CO and $\mathrm{PM}_{10}$ for the entire state over the period January 2010- December 2015 as shown in Figure 3.
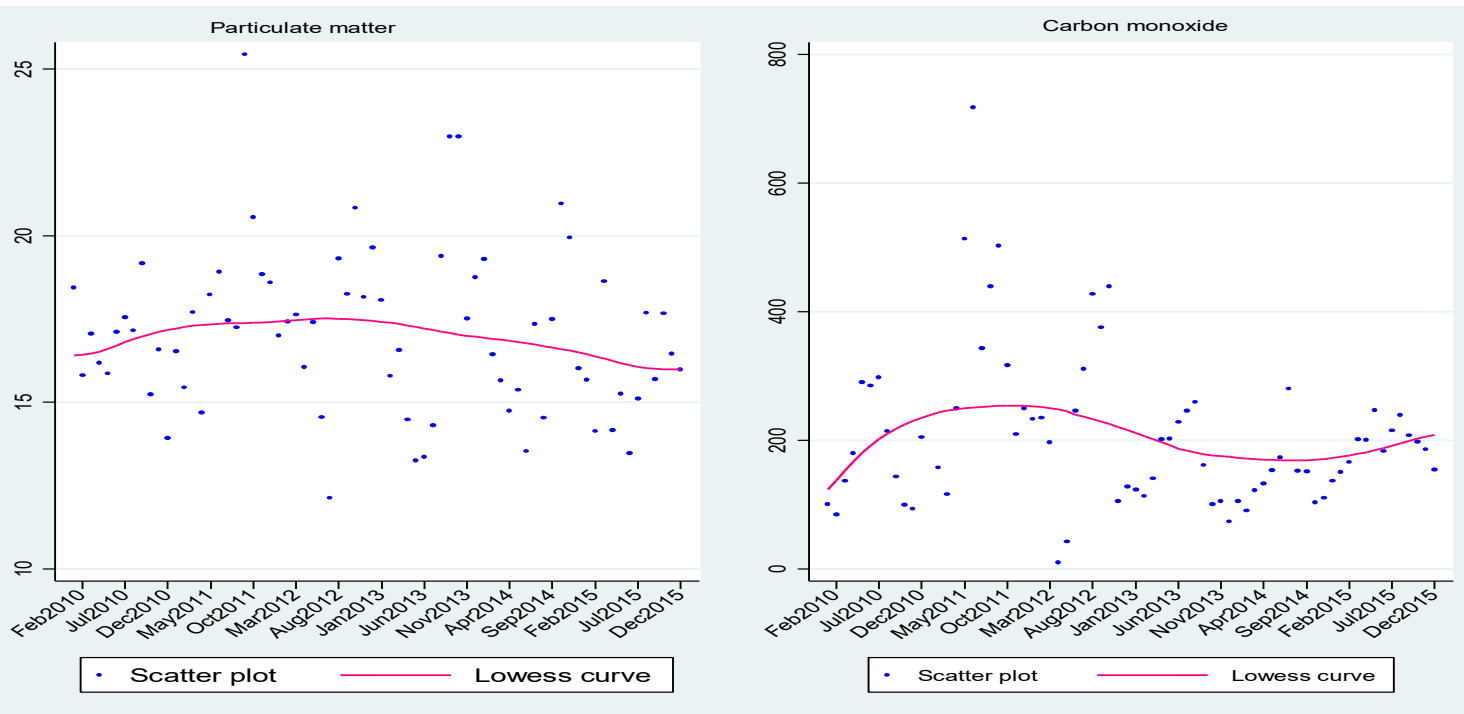
Figure 3: Trend and variations of PM10 and CO in the study period

The main weakness of this approach is that it represents a lower bound of the impact of pollution since pollution concentration in some areas might be higher than in other geographical locations. Despite this weakness, we argue that given the large population in South East Queensland, any impact of pollution will be observed among this population. Both $\mathrm{CO}$ and $\mathrm{PM}_{10}$ are standardised to $\mathrm{ug} / \mathrm{m} 3$ for ease of comparison. The Pairwise correlation coefficient between $\mathrm{PM}_{10}$ and $\mathrm{CO}$ is 0.210 ( $\mathrm{p}$-value $\left.<0.01\right)$.

In the analysis for acute exposure, we use the prevailing ambient air pollution during the month of the last separation to predict the probability of being readmitted within 3-12 months after being discharged. However, we use the prevailing amount of ambient air pollution during the month of initial admission to explore the impact of chronic exposure to air pollution on survival time, number of hospital admission and GP visits within the study window (2010 -2015). This exercise was necessary to have a contemporaneous estimate for the impact on air pollution on the acute and chronic event. For robustness checks, we later use air pollution at last admission and last separation respectively to tease out the lag length impact of pollution on health outcomes. Table 1 shows the description of variables used in the analysis.

Table 1: Description of variables

\begin{tabular}{|c|c|c|}
\hline Variable & Description & Measure \\
\hline \multicolumn{3}{|l|}{ Outcome variables } \\
\hline 3-month readmission & $\begin{array}{l}\text { Whether a patient was readmitted within } 3 \text { months after } \\
\text { being discharged from hospital }\end{array}$ & Binary \\
\hline 12-months readmission & $\begin{array}{l}\text { Whether a patient was readmitted within } 12 \text { months after } \\
\text { being discharged from hospital }\end{array}$ & Binary \\
\hline Death & Whether a patient died during the study window & Binary \\
\hline Hospital admissions & Number of hospital admissions during the study window & continuous \\
\hline GP visits & $\begin{array}{l}\text { Number of general practitioner visits during the study } \\
\text { window }\end{array}$ & continuous \\
\hline \multicolumn{3}{|l|}{ Pollution variables } \\
\hline $\mathrm{PM}_{10}$ & $\begin{array}{l}\text { Amount of particles less than } 10 \mu \mathrm{m} \text { in diameter }\left(\mathrm{PM}_{10}\right) \text { in } \\
\text { the atmosphere }\end{array}$ & continuous \\
\hline $\mathrm{CO}$ & Amount of carbon monoxide $(\mathrm{CO})$ in the atmosphere & continuous \\
\hline \multicolumn{3}{|l|}{ Control variables } \\
\hline Male & Whether the patient is a male & Binary \\
\hline Indigenous & Whether the patient is an indigenous Australian & Binary \\
\hline ICU admission & Whether the patient was admitted to intensive care unit & \\
\hline \multicolumn{3}{|l|}{ Age } \\
\hline $18-44$ & Whether the patient is age $18-44$ during admission & Binary \\
\hline $45-64$ & Whether the patient is age $45-64$ during admission & Binary \\
\hline $65-74$ & Whether the patient is age $65-74$ during admission & Binary \\
\hline$>74$ & Whether the patient is older than 74 years during admission & Binary \\
\hline $\begin{array}{l}\text { Private health facility } \\
\text { SEIFA index }{ }^{2}\end{array}$ & Whether the patient was admitted to a private hospital & Binary \\
\hline
\end{tabular}


Whether the patient lives in the first quintile of Binary socioeconomic advantage area

Whether the patient lives in the second quintile of Binary

Q2 socioeconomic advantage area

Whether the patient lives in the third quintile of Binary

Q3

socioeconomic advantage area

Whether the patient lives in the fourth quintile of Binary

Q4

socioeconomic advantage area

Whether the patient lives in the fifth quintile of Binary

\section{Results}

\subsection{Descriptive Results}

For our population with an index admission to hospital in 2010, the summary statistics in Table 2 shows that $19.3 \%$ of episodes were readmitted within 3 months after being discharged from the hospital while the corresponding 12 months readmission rates were $28.0 \%$. Our data is right censored with $77.3 \%$ of individuals surviving the study period with an average time-to-death of 60.69 months after the first admission. The average number of admissions and GP visits within the study window were 23 and 31 respectively. $51.4 \%$ were males, $2.4 \%$ indigenous Australians and the majority (51\%) were admissions at private health facilities. On average, $41.46 \%$ are within the working-age group (18-64 years old), 34.32\% aged above 74 years and $34.59 \%$ are of low socioeconomic status. 
Table 2: Summary statistics of variables used in the regression analysis

\begin{tabular}{lrr}
\hline Variables & Mean & Std. Dev. \\
\hline 3-month readmission & 0.193 & 0.395 \\
12-months readmission & 0.280 & 0.449 \\
Death & 0.227 & 0.418 \\
Hospital admissions & 23 & 41.732 \\
GP visits & 31 & 125 \\
PM 10 & $16.978 \mathrm{ug} / \mathrm{m}^{3}$ & $3.023 \mathrm{ug} / \mathrm{m}^{3}$ \\
CO & $206.619 \mathrm{ug} / \mathrm{m}^{3}$ & $116.795 \mathrm{ug} / \mathrm{m}^{3}$ \\
Male & 0.514 & 0.499 \\
Indigenous & 0.024 & 0.152 \\
ICU admission & 0.035 & 0.184 \\
Age & & \\
18-44 & 0.112 & 0.315 \\
45-64 & 0.304 & 0.460 \\
65-74 & 0.242 & 0.428 \\
>74 & 0.342 & 0.474 \\
Private health facility & 0.510 & 0.500 \\
SEIFA index & & \\
Q1 & 0.213 & 0.402 \\
Q2 & 0.201 & 0.401 \\
Q3 & 0.196 & 0.397 \\
Q4 & 0.191 & 0.400 \\
Q5 & 0.189 & 0.399 \\
\hline N
\end{tabular}

Note: GP is general practitioner; $\mathrm{PM}_{10}$ is particles less than $10 \mu \mathrm{m}$ in diameter; $\mathrm{CO}$ is carbon monoxide; ICU is intensive care unit; SEIFA is Socio-Economic Indexes for Areas.

\subsection{Impacts of acute exposure to air pollution on health}

We start our analysis by examining the impact of acute exposure to air pollution on the probability of a case being readmitted within 3 months and 12 months after discharge. Table 3 reports the coefficients of the Linear Probability Model (LPM), which are interpreted as a percentage increase or decrease in the probability of being readmitted to the hospital. The Fstatistics in all specifications shows that all covariates are jointly significant at $1 \%$ levels and the R-squared shows that the independent-variables explain about $16.7-32 \%$ variations in hospital readmissions. The results show that a one percent increase in $\mathrm{PM}_{10}$ is associated with 4.0 percentage points increase in the probability of being readmitted within 3 months after discharge. The corresponding increase in 12 months readmission associated with a one percent increase in $\mathrm{CO}$ is 1.1 percentage points. This positive association is significantly and largest for readmission within 12-month after discharge. A one percent increase in PM10 and CO is respectively associated with 8.8 and 3.0 percentage points increase in the probability of being readmitted with 12 months after discharge for the hospital. 
Table 3: Acute exposure to air pollution and health outcomes

\begin{tabular}{lcc}
\hline & 3-month readmission & 12-month readmission \\
\hline $\operatorname{Ln}\left(\mathrm{PM}_{10}\right)$ & $0.040^{* * * *}$ & $0.088^{* * *}$ \\
& $(0.008)$ & $(0.008)$ \\
$\mathrm{Ln}(\mathrm{CO})$ & $0.011^{* * *}$ & $0.030^{* * *}$ \\
& $(0.002)$ & $(0.002)$ \\
Mean of dependent variable & 0.193 & 0.280 \\
$\mathrm{~N}$ & 486,907 & 486,907 \\
$\mathrm{~F}-$ statistics & $396.16^{* * *}$ & $1029.54 * * *$ \\
$\mathrm{R}^{2}$ & 0.200 & 0.321 \\
Notes: All specifications include controls for age, gender, ethnicity, socioeconomic status, type of health facility, month \\
dummies, year trend. Robust standard errors are parentheses*** $\mathrm{p}<0.01, * * \mathrm{p}<0.05, * \mathrm{p}<0.1$.
\end{tabular}

\subsection{Impacts of chronic exposure to air pollution on health}

We now examine the impact of chronic exposure to air pollution on people with cardiovascular diseases. Column 1 in Table 4 presents the association between air pollution and the mortality risk within 72 months after the first CVD hospitalisation. For ease of interpretation, air pollution variables in this model are not logged, and all coefficients are converted to hazard ratios. The findings show that a one microgram per cubic metre increase in $\mathrm{PM}_{10}$ is associated with a $2.0 \%$ increase in the probability of death while a one microgram per cubic metre increase in CO is associated with $0.041 \%$ increase in the probability of death.

Columns 2-3 in Table 2 respectively report the impact of chronic exposure to air pollution on hospital admissions and GP visits in six years after the first CVD hospitalisation. In these two models, both dependent and pollution variables are logged values, hence, the reported coefficients are interpreted as elasticities. The results show that a one percent increase in $\mathrm{PM}_{10}$ is associated with $0.592 \%$ increase in the number of hospital admissions and $0.5 \%$ increase in the number of GP visits. The chronic impact of exposure to $\mathrm{PM}_{10}$ is significantly larger than that of CO. Chronic exposure to CO is associated with $0.098 \%$ increase hospital admissions and $0.073 \%$ increase in GP visits.

Table 4: Estimated association between air pollution and chronic health outcomes

\begin{tabular}{|c|c|c|c|}
\hline & $\begin{array}{l}\text { Death } \\
\text { (1) }\end{array}$ & $\begin{array}{l}\text { Ln (number of } \\
\text { Admissions) } \\
\text { (2) }\end{array}$ & $\begin{array}{c}\text { Ln (number of GP visits) } \\
\text { (3) }\end{array}$ \\
\hline $\mathrm{PM}_{10}$ & $\begin{array}{l}1.020 * * * \\
(0.005)\end{array}$ & $\begin{array}{c}0.592 * * * \\
(0.032)\end{array}$ & $\begin{array}{c}0.500 * * * \\
(0.038)\end{array}$ \\
\hline $\mathrm{CO}$ & $\begin{array}{l}1.00041^{* * * *} \\
(0.0001)\end{array}$ & $\begin{array}{c}0.098 * * * \\
(0.009)\end{array}$ & $\begin{array}{c}0.073 * * * \\
(0.009)\end{array}$ \\
\hline Mean of dependent variable & $0.029(60.56)$ & 23.67 & 30.96 \\
\hline
\end{tabular}




\begin{tabular}{lccc}
$\mathrm{N}$ & 484,828 & 487,131 & 487,131 \\
$\mathrm{~F}$-statistics & $6401.85^{* * *}$ & $116.44^{* * *}$ & $62.48^{* * * *}$ \\
$\mathrm{R}^{2}$ & $\mathrm{~N} / \mathrm{A}$ & 0.068 & 0.052 \\
\hline
\end{tabular}

Notes: All specifications include controls for age, gender, ethnicity, socioeconomic status, type of health facility, admission to ICU, month fixed effects and year trend. Robust standard errors are parentheses. Coefficients for the death outcome are hazard ratios. $* * * \mathrm{p}<0.01, * * \mathrm{p}<0.05, * \mathrm{p}<0.1$.

\subsection{Variations across types of CVD conditions}

We now examine the impact of pollution across different CVD conditions as reported in Table 5. The impact of acute exposure to $\mathrm{CO}$ has the most significant impact on readmission among people with heart failure (HF). A one percent increase in the exposure to CO increases the probability of HF patients being readmitted with $1.4-3.4$ percentage points. Patients with Cancer conditions suffer the most from acute exposure to $\mathrm{PM}_{10}$. PM10 increases readmission among cancer patients by $4.5-8.7$ percentage points. With regards to the long-term impact of exposure to air pollution, there is no clear pattern in the variations across different CVD conditions. For example, patients with coronary heart diseases (CHD) or cerebrovascular diseases (CeVD) are most likely to die within 72 months due to exposure to air pollutants, but such exposure largely increase the frequency of GP visits among patients with CHD or Atrial Fibrillation (AF). For those with chronic obstructive pulmonary disease (COPD), only PM10 significantly affects GP visits with the elasticity of 0.38 . In terms of hospital admissions, the largest impact is observed among patients with any form of cancer.

Table 5: Estimated impact of air pollution on health outcomes by CVD diseases

\begin{tabular}{|c|c|c|c|c|c|c|}
\hline Acute impacts & $\mathrm{HF}$ & CHD & Cancer $^{3}$ & COPD & $\mathrm{AF}$ & CeVD \\
\hline \multicolumn{7}{|l|}{ (Panel A) 3-month } \\
\hline \multicolumn{7}{|l|}{ readmission } \\
\hline \multirow[t]{2}{*}{$\operatorname{Ln}\left(\mathrm{PM}_{10}\right)$} & 0.030 & 0.013 & $0.045^{* *}$ & 0.020 & 0.021 & 0.022 \\
\hline & $(0.031)$ & $(0.020)$ & $(0.021)$ & $(0.029)$ & $(0.031)$ & $(0.039)$ \\
\hline \multirow[t]{2}{*}{$\mathrm{Ln}(\mathrm{CO})$} & $0.014 *$ & 0.007 & 0.007 & 0.004 & 0.010 & -0.005 \\
\hline & $(0.008)$ & $(0.005)$ & $(0.005)$ & $(0.006)$ & $(0.007)$ & $(0.007)$ \\
\hline $\mathrm{N}$ & 6,834 & 27,253 & 56,617 & 6,228 & 10,929 & 7,435 \\
\hline F-statistics & $15.2 * * *$ & $102.12 * * *$ & $88.88 * * *$ & $12.6^{* * *}$ & $57.14 * * *$ & $11.13 * * *$ \\
\hline $\mathrm{R}^{2}$ & 0.095 & 0.135 & 0.212 & 0.160 & 0.144 & 0.125 \\
\hline \multicolumn{7}{|l|}{ (Panel B) 12-month } \\
\hline \multicolumn{7}{|l|}{ readmission } \\
\hline $\operatorname{Ln}\left(\mathrm{PM}_{10}\right)$ & $\begin{array}{c}0.034 \\
(0.039)\end{array}$ & $\begin{array}{l}0.048^{* *} \\
(0.023)\end{array}$ & $\begin{array}{c}0.087 * * * \\
(0.018)\end{array}$ & $\begin{array}{l}0.065^{*} \\
(0.034)\end{array}$ & $\begin{array}{l}0.069^{*} \\
(0.036)\end{array}$ & $\begin{array}{c}0.038 \\
(0.040)\end{array}$ \\
\hline $\operatorname{Ln}(\mathrm{CO})$ & $\begin{array}{c}0.031 * * * \\
(0.009)\end{array}$ & $\begin{array}{c}0.026^{* * * *} \\
(0.006)\end{array}$ & $\begin{array}{c}0.025^{* * *} \\
(0.004)\end{array}$ & $\begin{array}{c}0.011 \\
(0.008)\end{array}$ & $\begin{array}{c}0.044^{* * * *} \\
(0.008)\end{array}$ & $\begin{array}{l}0.0001 \\
(0.008)\end{array}$ \\
\hline $\mathrm{N}$ & 6,834 & 27,253 & 56,617 & 6,228 & 10,929 & 7,435 \\
\hline F-statistics & $25.35 * * *$ & $161.8 * * *$ & $302.56^{* * *}$ & $17.47 * * *$ & $110.82 * * *$ & $15.29 * * *$ \\
\hline $\mathrm{R}^{2}$ & 0.157 & 0.205 & 0.373 & 0.271 & 0.263 & 0.156 \\
\hline \multicolumn{7}{|l|}{$\begin{array}{l}\text { Chronic impacts } \\
\text { (Panel C) time-to-death }\end{array}$} \\
\hline $\mathrm{PM}_{10}$ & $\begin{array}{c}1.026 \\
(0.024)\end{array}$ & $\begin{array}{l}1.051^{* *} \\
(0.025)\end{array}$ & $\begin{array}{l}1.003 \\
(0.012)\end{array}$ & $\begin{array}{l}1.037 \\
(0.031)\end{array}$ & $\begin{array}{l}1.007 \\
(0.037)\end{array}$ & $\begin{array}{l}1.065^{* *} \\
(0.030)\end{array}$ \\
\hline $\mathrm{CO}$ & $\begin{array}{l}1.0003 \\
(0.0005)\end{array}$ & $\begin{array}{l}1.000 \\
(0.0005)\end{array}$ & $\begin{array}{l}1.0005^{* *} \\
(0.0002)\end{array}$ & $\begin{array}{l}1.0004 \\
(0.0005)\end{array}$ & $\begin{array}{l}1.0004 \\
(0.0007)\end{array}$ & $\begin{array}{l}1.0009^{*} \\
(0.0005)\end{array}$ \\
\hline
\end{tabular}

\footnotetext{
${ }^{3}$ Although our data consist of cardiac patients, some of them had existing cancer conditions.
} 


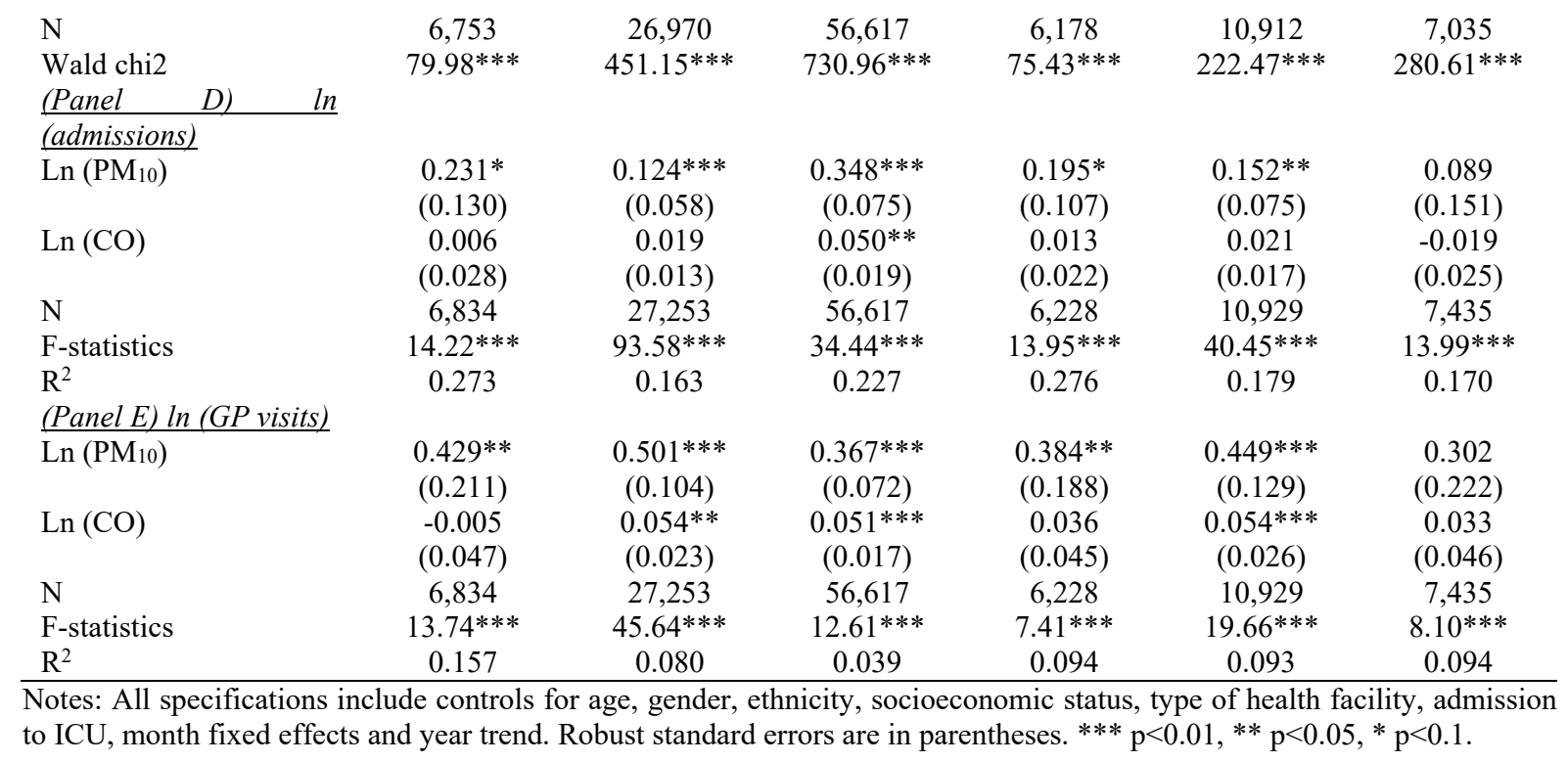

\subsection{Variations across places of residence}

Table 6 shows the results for the impact of air pollution on health outcomes across places of usual residence. Panels A-B reports acute events while Panels C-E show chronic health outcomes. The findings show that the impact of air pollution on acute events is larger among CVD patients residing in major cities than among those in regional and remote areas. A one percent increase in $\mathrm{PM}_{10}$ is associated with 6.5 percentage points increase in the probability of being readmitted to the hospital within 3 months after discharge while an increase in probability associated with $\mathrm{CO}$ is 1.3 percentage points. This positive association is mostly insignificant for those living in either regional or remote areas except the impact of $\mathrm{CO}$ on 3-month readmission among regional dwellers. A larger impact of air pollution is observed for 12-month readmission, which is consistent with the main findings in Table 3. For 12-month readmission, the impact is significant irrespective of place of residence, although larger for those in major cities.

Panel $\mathrm{C}$ shows that exposure to air pollution has a larger impact on survival time among people residing in major cities compared to those in regional and remote areas. Among patients living in major cities, a unit microgram per cubic meter increase in $\mathrm{PM}_{10}$ and $\mathrm{CO}$ is respectively associated with $3.1 \%$ and $0.038 \%$ increase in the probability of death within 72 months after the first CVD hospitalisation. The pattern of healthcare consumption due to exposure to air pollution is similar to that of mortality risk. For examples, among major city dwellers, a one percent increase in $\mathrm{PM}_{10}$ is associated with $0.645 \%$ increase in hospital admissions and $0.557 \%$ increase in GP visits in 6-years. The corresponding elasticities are lower among dwellers in 
regional and remote areas. The variations in the impact of $\mathrm{CO}$ on healthcare consumption across the place of residence mimics that of $\mathrm{PM}_{10}$

Table 6: Estimated impact of air pollution on health outcomes by place of residence

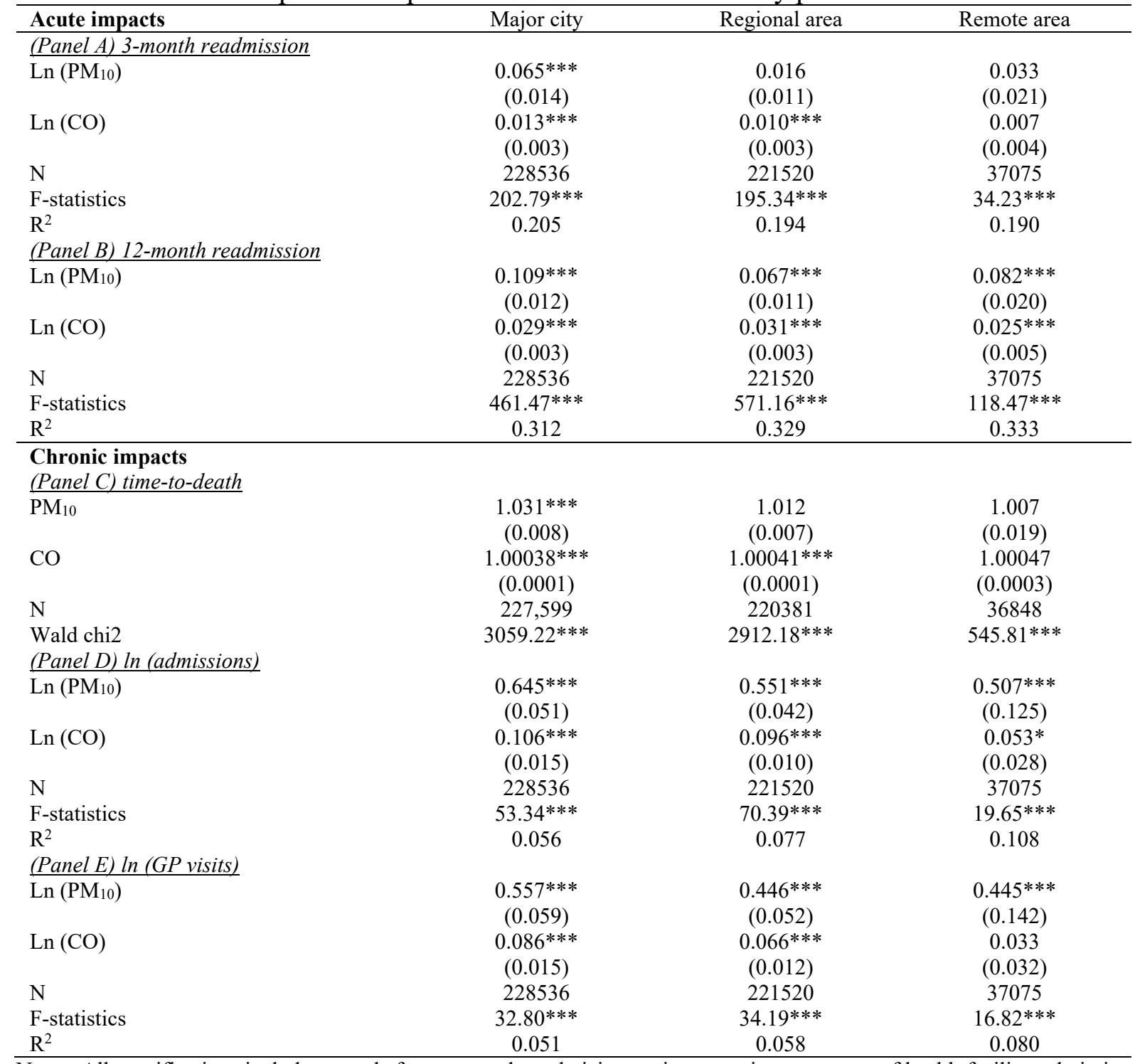

Notes: All specifications include controls for age, gender, ethnicity, socioeconomic status, type of health facility, admission to ICU, month fixed effects and year trend. Robust standard errors are in parentheses. ${ }^{* * *} \mathrm{p}<0.01,{ }^{*} \mathrm{p}<0.05,{ }^{*} \mathrm{p}<0.1$.

\subsection{Economic significance}

We now turn our attention to discuss the economic significance of the econometric estimates in Tables 3 and 4. That is, holding all other factors unchanged, we explore the magnitude/number of events associated with chronic exposure to air pollution, something that provides for policy directions. Appendix 2 shows a breakdown of air pollution by percentiles. The $25^{\text {th }}$ percentile air pollution corresponds with $15.5 \mathrm{ug} / \mathrm{m} 3 \mathrm{PM}_{10}$ and $122.99 \mathrm{ug} / \mathrm{m} 3$ of CO. Movement from the $25^{\text {th }}$ percentile to the $75^{\text {th }}$ percentile pollutant represents an increase of 
$17.80 \%$ for $\mathrm{PM}_{10}$ and a $103.26 \%$ increase in CO. Also, the change in air pollution between the $25^{\text {th }}$ percentile and $90^{\text {th }}$ percentile is equivalent to $25.5 \%$ and $178.88 \%$ increase in $\mathrm{PM}_{10}$ and CO. A careful look at Figure 1 shows that a change in air pollution, which is equivalent the difference between for example, $25^{\text {th }}$ and $90^{\text {th }}$ percentile pollutant occurs within 12 months and often within every 6 months or less. Same can be said about the differences across all percentiles, with changes far exceeding $1 \%$. This suggests that a $1 \%$ increase in $\mathrm{PM}_{10}$ and $\mathrm{CO}$ is a realistic variation in ambient air pollution, hence, our estimates are reliable.

We compute the number of events associated with chronic exposure to air pollution. Since our unit of analysis is at the individual level, we do not consider death because death is a terminal health state. Table 7 shows that an increase in air pollution from the $25^{\text {th }}$ percentile to $75^{\text {th }}$ percentile leads to a total of three of hospital admissions $(0.34$ for PM10 and 2.95 for $\mathrm{CO}$ ) and three GP visits (PM10: 0.43, CO:2.90) for a person with CVD. Similarly, chronic exposure to ambient air pollutant equivalent to the difference between the $25^{\text {th }}$ percentile and 90th percentile pollution is associated with six hospital admissions ( $\left.\mathrm{PM}_{10}: 0.55, \mathrm{CO}: 5.12\right)$ and six number of GP visits (PM10: 0.61, CO: 4.98).

Table 7: Total chronic events attributable to exposure air pollution by percentiles of air pollution

\begin{tabular}{ccccccc}
\hline & \multicolumn{3}{c}{ Hospital admissions } & \multicolumn{3}{c}{ GP visits } \\
\hline Percentiles & $\mathrm{PM}_{10}$ & CO & Total & PM $_{10}$ & CO & Total \\
\hline $25^{\text {th }}-50^{\text {th }}$ & 0.225 & 1.456 & 1.681 & 0.249 & 1.418 & 1.667 \\
$25^{\text {th }}-75^{\text {th }}$ & 0.340 & 2.946 & 3.336 & 0.430 & 2.870 & 3.301 \\
$25^{\text {th }}-90^{\text {th }}$ & 0.553 & 5.106 & 5.659 & 0.611 & 4.975 & 5.586 \\
\hline
\end{tabular}

\subsection{Cost implications of chronic exposure to air pollution}

We now analyse the healthcare costs associated with chronic exposure to air pollution. This analysis focuses on the cost of consuming health services such as hospital admissions, GP visit and its analysed from the health service perspective. From the hospital data the mean total cost per admission is estimated as $\$ 2,358$ (CI: $\$ 2,332-\$ 2384)^{4}$, which is the sum of direct hospital cost (\$1989) and hospital overhead cost (\$369). In addition, a GP short visit (item 23 of the medical benefit schedule) cost of $\$ 37.05$ is used [26] because more than $61 \%$ of patients in our data utilise this service.

Using these figures, we can provide back-of-the-envelope estimates for direct healthcare cost of CVD accounted for by chronic exposure to air pollution. As summarised in

\footnotetext{
${ }^{4}$ Confidence intervals of the mean costs were estimated a nonparametric bootstrapping approach with 1000 replications. All cost figures were reported using Australian Dollars, 2015 prices.
} 
Table 7, chronic exposure to $\mathrm{PM}_{10}$ and $\mathrm{CO}$ at the level equivalent to the $25^{\text {th }}$ and $75^{\text {th }}$ percentile difference, result in additional costs $\$ 7,867$ on admission and $\$ 122$ on GP visits per patient. The corresponding costs of hospital admissions and GP visits for air pollution equivalent to the $25^{\text {th }}-90^{\text {th }}$ percentile difference is $\$ 13,347$ and $\$ 207$ on GP visits per patient.

At the population level, the estimates suggest that air pollution equivalent of the $25^{\text {th }}$ $75^{\text {th }}$ percentile difference costs the state $\$ 591$ million on admission, and $\$ 9$ million on GP visits while air pollutants equivalent of the $25^{\text {th }}-90^{\text {th }}$ percentile difference costs $\$ 1.0$ billion on admissions and $\$ 15$ million on GP visits. That is, if air pollution were to be maintained at the $25^{\text {th }}$ percentile $\mathrm{p}$ level $\left(15.45 \mathrm{ug} / \mathrm{m} 3\right.$ for $\mathrm{PM}_{10}$ and $122.49 \mathrm{ug} / \mathrm{m} 3$ for $\left.\mathrm{CO}\right)$, it would lead to a cost-savings of $\$ 1.018$ billion to the Queensland state.

Table 7: Analysis of healthcare costs attributable to chronic exposure to air pollution

\begin{tabular}{|c|c|c|c|c|c|c|c|c|}
\hline \multicolumn{5}{|c|}{ Hospital admissions } & \multicolumn{4}{|c|}{ GP visits } \\
\hline $\begin{array}{l}\text { Air } \\
\text { pollution } \\
\text { level }\end{array}$ & $\begin{array}{l}\mathrm{PM}_{10} \\
\$\end{array}$ & $\begin{array}{l}\mathrm{CO} \\
\$\end{array}$ & $\begin{array}{l}\text { Total } \\
\$\end{array}$ & $\begin{array}{l}\text { Population } \\
(\mathrm{N}=75140) \$\end{array}$ & $\begin{array}{l}\mathrm{PM}_{10} \\
\$\end{array}$ & $\begin{array}{l}\mathrm{CO} \\
\$\end{array}$ & $\begin{array}{l}\text { Total } \\
\$\end{array}$ & $\begin{array}{l}\text { Population } \\
(\mathrm{N}=75140) \$\end{array}$ \\
\hline $25^{\text {th }}-50^{\text {th }}$ & 532 & 3433 & 3,965 & $297,926,277$ & 9 & 53 & 62 & $4,642,015$ \\
\hline $25^{\text {th }}-75^{\text {th }}$ & 919 & 6,948 & 7,867 & $591,092,525$ & 16 & 106 & 122 & $9,188,789$ \\
\hline $25^{\text {th }}-90^{\text {th }}$ & 1,305 & 12,042 & 13,347 & $1,002,893,718$ & 23 & 184 & 207 & $15,551,412$ \\
\hline
\end{tabular}

\section{Robustness checks and additional results}

\subsection{Potential lag effect of air pollution}

Our main findings as discussed so far, assume that the impact of air pollution on health outcomes is contemporaneous. It is possible that there is a delayed impact of air pollution on health outcomes, something which is partly, explained by the larger marginal effects estimated for 3-months readmission compared with 12-months readmissions. Ideally, using lagged air pollution would pick up such delayed effects. However, considering that our data is hospital admissions and highly imbalanced, hence including lag would result in great loss of observation. ${ }^{5}$ Thus, using lagged admission leads to a very small sample which could lead to a potential biased estimate. Despite this weakness, we use air pollution data at the month of the admission (instead of month of separation) for acute events and last separation (instead of month of initial admission) for chronic events as a robustness check. The results in Panel A-B in Table 8 show that the impacts of $\mathrm{PM}_{10}$ and $\mathrm{CO}$ at last admission on 3-month and 12-month

\footnotetext{
${ }^{5}$ About $70 \%$ of observations will be dropped from the analysis if we form monthly panel data and take the first lag.
} 
readmissions do not significantly vary from our main findings in Table 1. With regards to chronic outcomes, we find that the impact of air pollution at last separation on time-to-death is lower than our core finding, however, it predicts higher admissions than pollutions at admissions. The findings on GP visits within six years do not vary from the main findings. The relatively stable coefficients are probably because most of the patients are not admitted for more than one month, hence, there is not much variation between the admission and separation months.

\subsection{Omitted variable bias}

Although our estimated adverse health outcomes rely on variations in ambient air pollution, it is possible that such an association is confounded by indoor air pollution. In all estimations, we have clustered the standard errors at the individual level to minimise such confounding biases, however, this approach will not be able to isolate the impact indoor air pollutants from ambient air pollutant because their sources are likely to be different. Not isolating the confounders can lead to omitted variable bias model specification. Hence, we follow the approach by Janke [6] and Beatty and Shimshack [9] and include confounding weather variables such as temperature and amount of cloud in the atmosphere clouds. These variables are likely to predict indoor air quality. For example, during an extremely hot temperature, individuals may open their windows for cooler air, especially those without air conditioners $^{6}$, which will intend to allow ambient pollutant to enter their rooms. Also, since these variables are likely to directly impact health outcomes [27, 28], they may confound the association between air pollution and health outcomes. In addition to ambient temperature, we include unemployment rate to isolate any macroeconomic shock that could impact health outcomes [29-33] As shown in Table 8, estimated marginal effects, hazard ratio, and elasticities are slightly larger than in those in Tables 1 and 2, which suggests that our benchmark findings are a lower bound of the association between air pollution and health outcomes. Also, the standard errors and R-squared in these tables are relatively stable, indicating that omitted variables do not bias our findings.

\subsection{Isolating unobservable time invariant Local Government Area (LGA) effects}

Our analysis utilises variations in air pollution at the state-level, which means that there could be some biases is some LGAs may have high levels of pollution and poor health status.

\footnotetext{
${ }^{6}$ We have also controlled for the individual's socioeconomic status in our models.
} 
Since there are not many monitoring stations in Queensland, we cannot use monitoring station fixed effects to isolate these unobservable characteristics. It is possible that there are systematic lifestyle differences across local areas and are time-invariant (e.g., city vs. rural or remote areas) which may affect health outcomes. We, therefore, examine the impact of the unobserved heterogeneity within different local government areas on our estimates by performing a twoway clustering. By this approach, we are able to allow for dependence within Local Government Areas (LGAs), which are sub-state administrative boundaries, and individuals simultaneously [34]. The findings in Panel C of Table 8 show that all the standard errors are stable and not different from those in Tables 1 and 2. Similarly, the estimated marginal effects, hazard ratios and elasticities do not vary significantly from our core findings, hence, unobservable time-invariant characteristics do not bias our findings.

\subsection{Excluding Moranbah from the analysis}

Since Moranbah experienced an upsurge in $\mathrm{PM}_{10}$ in 2012 due to the housing estate development around the monitoring station, it is possible this shock could bias our estimates. We repeated the analysis by excluding Moranbah as reported in Panel D in Table 8. The results do not change and are similar to the main finding. This is partly because Moranbah is a small town and only 271 admissions were from Moranbah. ${ }^{7}$

\subsection{Using parametric survival models}

We also test for the robustness of our survival model by using parametric survival models other than the semi-parametric Cox proportional hazard model. Specifically, we use three different models with different distributional assumptions: Gompertz, Weibull, and Exponential. All models produced similar hazard ratio and standard errors, with variations in the AIC and BIC as shown in Appendix 3. This suggests that irrespective of the assumption put on the distribution of the survival time-to-death, our estimated impact of air pollution on death happening within 72 months after index hospitalisation is reliable.

\subsection{Achieving modest levels of pollution}

\footnotetext{
${ }^{7}$ We also estimated a separate analysis for Moranbah, but the results were not statistically significant because of the very small sample for Moranbah.
} 
To policymakers, reducing pollution to the $25^{\text {th }}$ percentile might be challenging and perhaps, will be a long-term policy strategy. Therefore, we look at a reasonably feasible reduction the median $\left(50^{\text {th }}\right.$ percentile) pollution rather than the $25^{\text {th }}$ percentile. Similarly, using back-of-the-envelope approach Appendix 4 shows that a strict environmental policy that aims to reduce pollution to the 50th percentile $\left(\mathrm{PM}_{10}-17.06 \mathrm{ug} / \mathrm{m} 3: \mathrm{CO}-185.74 \mathrm{ug} / \mathrm{m} 3\right)$ will help avoid 4 hospital admissions and 3 GP visits per patient and will lead to a cost saving of $\$ 940$ million to the health sector.

Table 8: Estimated association between air pollution and health outcomes

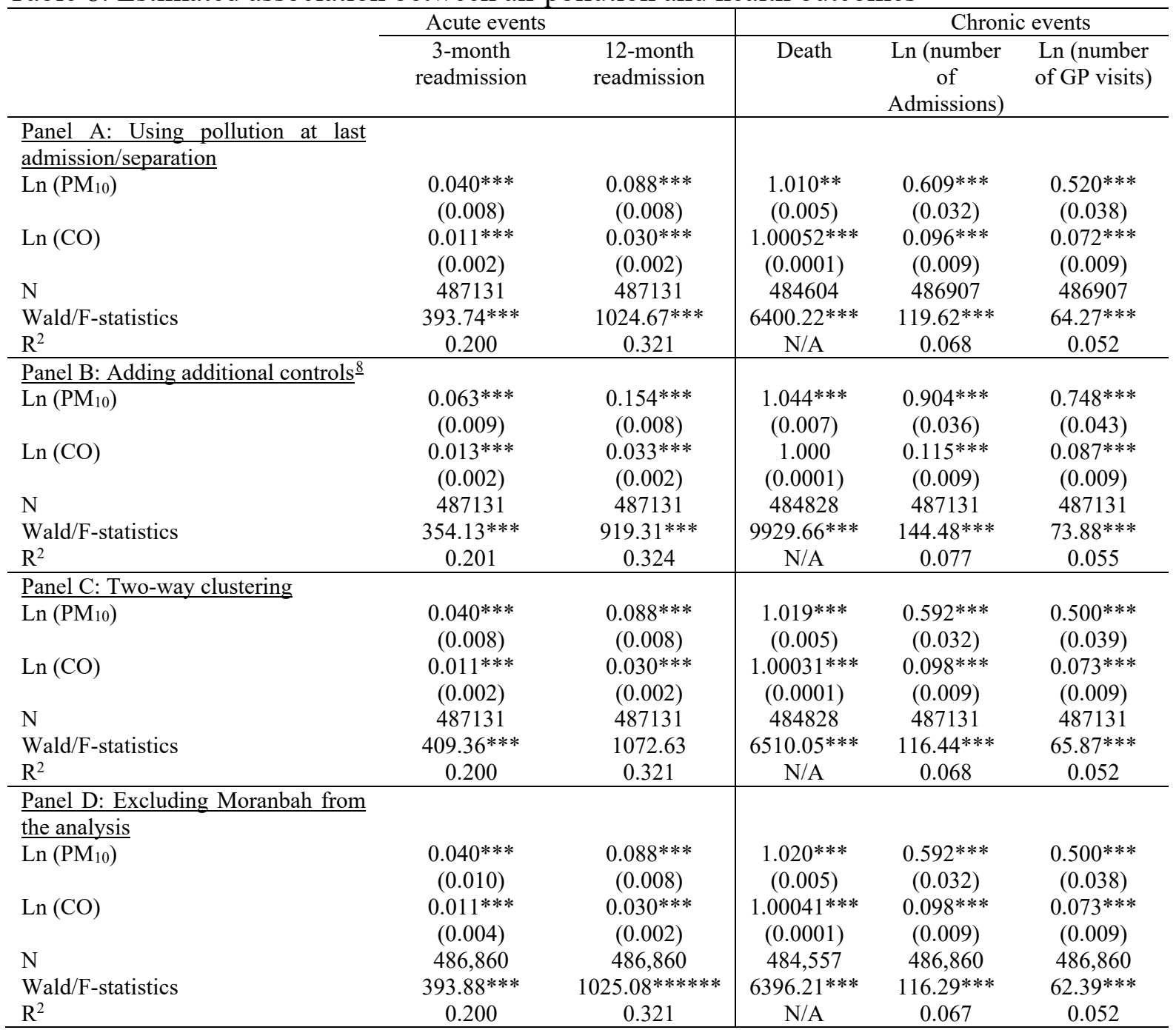

Notes: All specifications include controls for age, gender, ethnicity, socioeconomic status, type of health facility, month dummies, year trend. Robust standard errors are in parentheses. ${ }^{* * *} \mathrm{p}<0.01,{ }^{* *} \mathrm{p}<0.05, * \mathrm{p}<0.1$.

\footnotetext{
${ }^{8}$ Additional control variables included are monthly ambient temperature, monthly clouds in the atmosphere, monthly state-level unemployment rate.
} 


\section{Discussion and conclusion}

Australia has clean air, but the current levels are not safe enough for people with heart disease. This study has utilised cohort data of CVD patients who were first hospitalised with any CVD condition in 2010 with follow up admission until 2015 to demonstrate the impacts of acute and chronic exposures to pollution on people's health.

The key findings from the study are: First, acute exposure to air pollution increase the chances of hospital readmissions within 3-12 months. That is, people with heart diseases are at risk of being readmitted to the hospital when they are exposed to outdoor pollutants. Those suffering from CHD, COPD, AF or cancer and live in major cities are most vulnerable to readmission after short exposure to pollution. Second, people with heart diseases are at risk of deaths in 72 months after first hospitalisation if chronically exposed to pollution. The most vulnerable groups are those CHD or CeVD. Third, exposure to extreme levels of pollution increases the use of health services among heart diseases. This is equivalent to six hospital admissions and six GP visits after the first admission. Finally, this study estimates that air pollution accounts for a significant amount of healthcare expenditure in Queensland. That is, if the current air pollution levels were to be lowered, cost-saving of $\$ 1.3$ billion would be accrued to the health sector. Even at the modest level of pollution, a total savings of $\$ 900$ million could be generated with this saving coming from a reduction in hospital admission and GP visits alone.

Comparing our estimates with previous studies on adult mortality, Janke, Propper [10] found that $\mathrm{PM}_{10}$ was associated with a $2.7 \%$ increase in all-cause mortality at the local authority level in England. Our estimate of $2.0 \%$ is slightly lower than their estimates, which is partly due to the short follow up period for the cohort in our study. However, our finding that $\mathrm{PM}_{10}$ is associated with $5.1 \%$ increase in the hazard of death for people with CHD is close to the estimate of 4-5\% increase in CHD mortality found in England by Janke, Propper [10]. Although limited studies have explored pollution and adults' hospital admissions, studies from California children's admission show that exposure to $\mathrm{CO}$ is linked with $5-14 \%$ increase in asthma admissions [5]. This is larger than our adults' CVD admissions at 0.098\%. With regards to hospital admissions, Filippini, Masiero [12] did not find any correlation between $\mathrm{PM}_{10}$ and among patient with cardiovascular disease in Switzerland. Our finding shows a significant link between exposure to $\mathrm{PM}_{10}$ and hospital admission, which is partly explained by the high concentration of $\mathrm{PM}_{10}$ in Queensland due to bush fires and dust storms. 
The strengths of our study lie in the richness of our data which allow us to focus on health outcomes such as hospital readmissions and GP visits which are rarely examined but have a significant negative impact on the health sector. In addition, we have applied a novel research design to unravel the impact of pollution on death for people with heart disease. Finally, the cost-savings analysis offers a policy insight on the potential benefits of formulating policies that can minimise the pollution concentration as well as mitigates the consequences of exposure to ambient pollution.

Despite these strengths of our study, some weaknesses are acknowledged. First, the estimates reported here are based on CVD patients who were hospitalised in 2010, hence, those who were not hospitalised are excluded from the study. Our results may change if the characteristics of those who were not hospitalised are considered. Second, due to the retrospective nature of our data, we are unable to disentangle the impact of the interaction between migration and pollution on health outcomes. That is, we have assumed that patients do not migrate during the entire study period and that any pollution effect observed is coming from pollution in Queensland. Other supply-side confounding factors such as access to posthospitalisation cardiac services including disease management programs and cardiac exercise programs are also lacking in our data but may have substantial impact on post-hospitalisation healthcare utilisation and outcomes. Finally, the time-series nature of our measure for pollution masks up within state variations in pollution, for example across different locations. We are unable to resolve this weakness due to the very few numbers of monitoring stations in Queensland. As mentioned earlier, there are only two monitoring stations for CO in the state of Queensland. However, we believe that after controlling for several individual-level confounding factors, any potential biases are minimized.

This notwithstanding, our study offers some policy directions, especially considering the recent upsurge in bush fires and dust storms in Queensland and Australia. Environmental policies that seek to minimise the emission of ambient air pollutants could be tailored toward encouraging people to use alternative means of transport such as biking, walking or taking the bus instead of driving. This is because the largest contributor of $\mathrm{CO}$ is human activities from motor vehicles. Also, considering that $\mathrm{PM}_{10}$ comes mostly from bush fires and dust storms, smog alerts can be issued in Queensland whenever pollution concentration levels exceed the levels specified in the NEPM air quality standards as done in other states like California. 


\section{Reference}

1. WHO, Global Health Observatory (GHO) data. 2020.

2. Currie, J. and M. Neidell, Air pollution and infant health: what can we learn from California's recent experience? The Quarterly Journal of Economics, 2005. 120(3): p. 1003-1030.

3. Huynh, Q.L., et al., Association of ambient particulate matter with heart failure incidence and all-cause readmissions in Tasmania: an observational study. BMJ open, 2018. 8(5): p. e021798.

4. $\quad$ Australian Institute of Health and Welfare, Cardiovascular disease. Cat. no. CVD 83. . 2019: Canberra.

5. Neidell, M., Air pollution, health, and socio-economic status: the effect of outdoor air quality on childhood asthma. Journal of health economics, 2004. 23(6): p. 1209-1236.

6. Janke, K., Air pollution, avoidance behaviour and children's respiratory health: Evidence from England. Journal of health economics, 2014. 38: p. 23-42.

7. Coneus, K. and C.K. Spiess, Pollution exposure and child health: Evidence for infants and toddlers in Germany. Journal of Health Economics, 2012. 31(1): p. 180-196.

8. Currie, J., M. Neidell, and J. Schmieder, Air pollution and infant health: Lessons from New Jersey. Journal of health economics, 2009. 28(3): p. 688-703.

9. Beatty, T.K.M. and J.P. Shimshack, Air pollution and children's respiratory health: A cohort analysis. Journal of Environmental Economics Management, 2014. 67(1): p. 39-57.

10. Janke, K., C. Propper, and J. Henderson, Do current levels of air pollution kill? The impact of air pollution on population mortality in England. Health Economics, 2009. 18(9): p. 1031-1055.

11. Kim, Y., et al., Long-run health consequences of air pollution: Evidence from Indonesia's forest fires of 1997. Economics \& Human Biology

2017. 26: p. 186-198.

12. Filippini, M., G. Masiero, and S. Steinbach, The impact of ambient air pollution on hospital admissions. The European Journal of Health Economics, 2019. 20(6): p. 919-931.

13. Spengler, J.D. and K. Sexton, Indoor air pollution: a public health perspective. Science, 1983. 221(4605): p. 9-17.

14. WHO, Carbon monoxide. 2000. http://www.euro.who.int/ data/assets/pdf file/0020/123059/AQG2ndEd 5 5carbonmon oxide.PDF.

15. QGSE, Carbon monoxide concentrations. $2019 . \quad$ p. https://www.stateoftheenvironment.des.qld.gov.au/pollution/air-quality/carbon-monoxideconcentrations.

16. QGSE, Particulate concentrations. $2019 . \quad$ p. https://www.stateoftheenvironment.des.qld.gov.au/pollution/air-quality/particulateconcentrations.

17. Chin, M.T., Basic mechanisms for adverse cardiovascular events associated with air pollution. Heart, 2015. 101(4): p. 253-256.

18. AlHW, Transition between hospital and community care for patients with coronary heart disease: New South Wales and Victoria, 2012-2015. 2018.

19. Kaufman, J.D., et al., Association between air pollution and coronary artery calcification within six metropolitan areas in the USA (the Multi-Ethnic Study of Atherosclerosis and Air Pollution): a longitudinal cohort study. The Lancet, 2016. 388(10045): p. 696-704.

20. Gill, E.A., et al., Air pollution and cardiovascular disease in the Multi-Ethnic Study of Atherosclerosis. Progress in cardiovascular diseases, 2011. 53(5): p. 353-360.

21. Caudill, S.B., Practitioners corner: An advantage of the linear probability model over probit or logit. Oxford Bulletin of Economics Statistics, 1988. 50(4): p. 425-427.

22. Afoakwah, C., X. Deng, and I. Onur, Women's Bargaining Power and Children's Schooling Outcomes: Evidence From Ghana. Feminist Economics, 2020: p. 1-29. 
23. Hsieh, C., et al., A cohort study of adult patients with severe dengue in Taiwanese intensive care units: the elderly and APTT prolongation matter for prognosis. PLoS Neglected Tropical Diseases, 2017. 11(1): p. e0005270.

24. Cain, K.C., et al., Bias due to left truncation and left censoring in longitudinal studies of developmental and disease processes. American journal of epidemiology, 2011. 173(9): p. 1078-1084.

25. Byrnes, J., et al., Queensland Cardiovascular Data Linkage (QCard): A population-based cohort study [version 1; peer review: awaiting peer review]. F1000Research 2020. 9(282).

26. MBS, Medical Benefits Scheme. 2019.

27. Gasparrini, A., et al., Mortality risk attributable to high and low ambient temperature: a multicountry observational study. The Lancet, 2015. 386(9991): p. 369-375.

28. Huynen, M.-M., et al., The impact of heat waves and cold spells on mortality rates in the Dutch population. Environmental health perspectives, 2001. 109(5): p. 463-470.

29. Ruhm, C.J., Are recessions good for your health? Quarterly Journal of Economics, 2000. 115(2): p. 617-650.

30. Neumayer, E., Recessions lower (some) mortality rates: evidence from Germany (vol 58, pg 1037, 2004). Social Science \& Medicine, 2004. 59(9): p. 1993-1993.

31. Gerdtham, U.G., \& Johannesson, M., Business cycles and mortality: results from Swedish microdata. Social science \& medicine, 2005. 60(1): p. 205-218.

32. Van den Berg, G.J., et al., Mortality and the business cycle: Evidence from individual and aggregated data. Journal of health economics, 2017. 56: p. 61-70.

33. Ariizumi, H. and T. Schirle, Are recessions really good for your health? Evidence from Canada. Social Science \& Medicine, 2012. 74(8): p. 1224-1231.

34. Cameron, A.C. and D. Miller, A practitioner's guide to cluster-robust inference. Journal of Human Resources, 2015. 50(2): p. 317-372. 


\section{Appendices}

Appendix Table 1: Logit regression for acute exposure to air pollution and health outcomes

\begin{tabular}{lcc} 
& $\begin{array}{c}\text { 3-month readmission } \\
\text { (marginal effects) }\end{array}$ & $\begin{array}{c}\text { 12-month readmission } \\
\text { (marginal effects) }\end{array}$ \\
\hline $\operatorname{Ln}\left(\mathrm{PM}_{10}\right)$ & $0.042^{* * *}$ & $0.089^{* * *}$ \\
& $(0.008)$ & $(0.008)$ \\
$\mathrm{Ln}(\mathrm{CO})$ & $0.011^{* * *}$ & $0.029^{* * *}$ \\
$\mathrm{~N}$ & $(0.002)$ & $(0.002)$ \\
Wald chi2 & 486,907 & 486,907 \\
Pseudo $\mathrm{R}^{2}$ & $9549^{* * *}$ & $18153.14^{* * *}$ \\
Notes: All specifications include controls for age, gender, ethnicity, socioeconomic status, type of health facility, month
\end{tabular}
dummies, year trend. Robust standard errors are parentheses ${ }^{* * *} \mathrm{p}<0.01,{ }^{* *} \mathrm{p}<0.05,{ }^{*} \mathrm{p}<0.1$. 
Appendix 2: Summary statistics for air pollution

\begin{tabular}{lcccccc}
\hline & Min & $25^{\text {th }}$ percentile & $50^{\text {th }}$ percentile & $75^{\text {th }}$ percentile & $90^{\text {th }}$ percentile & Max \\
\hline $\mathrm{PM}_{10}$ & 12.13 & 15.45 & 17.06 & 18.23 & 19.40 & 25.44 \\
$\mathrm{CO}$ & 10.28 & 122.99 & 185.74 & 249.99 & 343.10 & 717.98 \\
\hline
\end{tabular}


Appendix 3: Estimated association between air pollution and survival time using different survival models

\begin{tabular}{lccc}
\hline & Gompertz & Weibull & Exponential \\
\hline $\mathrm{PM}_{10}$ & $1.020 * * *$ & $1.020 * * *$ & $1.020 * * *$ \\
$\mathrm{CO}$ & $(0.005)$ & $(0.005)$ & $(0.005)$ \\
& $1.00041 * * *$ & $1.00040 * * *$ & $1.00045^{* * *}$ \\
Mean of dependent variable & $(0.0001)$ & $(0.0001)$ & $(0.0001)$ \\
$\mathrm{N}$ & 0.029 & 0.029 & 0.029 \\
Wald test $(\chi 2)$ & 484828 & 484828 & 484828 \\
AIC & $6385.43 * * *$ & $6409.68 * * *$ & $6391.47 * * *$ \\
BIC & 136182.5 & 135652.2 & 136752.3 \\
\hline
\end{tabular}

Notes: All specifications include controls for age, gender, ethnicity, socioeconomic status, type of health facility, admission to ICU, month fixed effects and year trend. Robust standard errors are in parentheses. $* * * \mathrm{p}<0.01, * * \mathrm{p}<0.05, * \mathrm{p}<0.1$. AIC $=$ Akaike's Information Criterion, BIC= Bayesian Information Criterion. 
Appendix 4: Total chronic events attributable to exposure air pollution by percentiles of air pollution

\begin{tabular}{lcccl|llllll}
\hline \multicolumn{4}{c|}{ Hospital admissions } & \multicolumn{5}{c}{ GP visits } \\
\hline $\begin{array}{l}\text { Air pollution } \\
\text { level }\end{array}$ & $\mathrm{PM}_{10}$ & $\mathrm{CO}$ & Total & $\begin{array}{l}\text { Cost } \\
\text { per } \\
\text { patient }\end{array}$ & $\begin{array}{l}\text { Health sector } \\
\text { cost } \\
\text { \$million }\end{array}$ & $\mathrm{PM}_{10}$ & $\mathrm{CO}$ & Total & $\begin{array}{l}\text { Cost } \\
\text { per } \\
\text { patient }\end{array}$ & $\begin{array}{l}\text { Health } \\
\text { sector cost } \\
\text { \$million }\end{array}$ \\
& & & & & & & & & & \\
\hline $50^{\text {th }}-75^{\text {th }}$ & 0.2 & 1.5 & 1.7 & 5,027 & 378 & 0.3 & 1.4 & 1.7 & 178 & 13 \\
$50^{\text {th }}-90^{\text {th }}$ & 0.4 & 3.7 & 3.9 & 12,089 & 908 & 0.4 & 2.9 & 3.3 & 427 & 32 \\
\hline
\end{tabular}

